\title{
Schistosoma japonicum risk in Jiangsu province, People's Republic of China: identification of a spatio-temporal risk pattern along the Yangtze River
}

\author{
Kun Yang ${ }^{1}$, Le-Ping Sun ${ }^{1}$, You-Sheng Liang ${ }^{1}$, Feng $\mathrm{Wu}^{1}$, Wei $\mathrm{Li}^{1}$, Jian-Feng Zhang ${ }^{1}$, Yi-Xin \\ Huang $^{1}$, De-Rong Hang ${ }^{1}$, Song Liang ${ }^{2}$, Robert Bergquist ${ }^{3}$, Xiao-Nong Zhou ${ }^{4}$ \\ ${ }^{1}$ Jiangsu Institute of Parasitic Diseases, Key Laboratory of Parasitic Disease Control and Prevention, Jiangsu \\ Provincial Key Laboratory of Parasite Molecular Biology, Wuxi, People's Republic of China; ${ }^{2}$ Department of \\ Environmental and Global Health, College of Public Health and Health Professions, Emerging Pathogens \\ Institute, University of Florida, Gainesville, USA; Ingerod, Brastad, Sweden; ${ }^{4}$ National Institute of Parasitic \\ Diseases, Chinese Center for Disease Control and Prevention, Shanghai, People's Republic of China
}

\begin{abstract}
The risk for Schistosoma japonicum infection in Jiangsu province, People's Republic of China, was investigated by a mouse bioassay. Various investigations were conducted in the period 2009-2011 with the presentation here representing the summary of the results from 45-50 sites in the marshlands along the Yangtze River's course through the province. Indices representing three aspects of the infection were collected to assess risk: (i) the proportion of sentinel points where at least one mouse infection was recorded; (ii) the proportion of infected mice at each of these sites; and (iii) the average worm burdens. Directional distribution analysis and scan statistics were used to explore the spatio-temporal risk pattern. The spatial distribution was oriented along the Yangtze River and the directional distributions for the proportion of infected mice and mean worm burdens were similar for the positive sentinel sites. Four statistically significant clusters were detected in 2009, but only one in 2010 and 2011, respectively. Temporal windows for infection risk were seen in June and September. The study illustrates the utility of spatio-temporal analysis in assessing the risk for schistosomiasis. This approach should be useful with respect to surveillance and response that can be expected to be increasingly applied when moving from morbidity control to transmission control.
\end{abstract}

Keywords: schistosomiasis, mice bioassays, spatio-temporal analysis, schistosomiasis transmission control, risk area, People's Republic of China.

\section{Introduction}

Schistosomiasis japonica is a zoonotic disease caused by infection with the trematode parasite Schistosoma japonicum, which depends on Oncomelania hupensis snails as its intermediate host. The snails release cercariae, which infect humans by penetrating the skin during water contact such as fishing, cultivating crops, cutting weeds, washing clothes, swimming, etc. The disease was once a major public health problem in the People's Republic of China (P.R. China) with up to 12 million cases, but the number of infected people has gradually been reduced to less than

Corresponding author:

Xiao-Nong Zhou

National Institute of Parasitic Diseases

Chinese Center for Disease Control and Prevention

Reijin No.207 road - 20025 Shanghai, People's Republic of China

Tel. +86216473 8058; Fax +862164332670

E-mail: ipdzhouxn@sh163.net
500,000 (Utzinger et al., 2005). However, approximately 65 million individuals are still at risk (Zhou et al., 2005, 2007). Schistosomiasis remains endemic in many, limited foci in the hilly and mountainous regions in Sichuan and Yunnan provinces, but the main problem is in the marshlands and lakes in the eastern and central parts of the country, where elimination of transmission has proved difficult to achieve (Utzinger et al., 2005; Hao et al., 2006). Here, more than $80 \%$ of all current cases in the country are found in a wide belt covering the provinces of Hunan, Hubei, Jiangxi, Anhui and Jiangsu.

Jiangsu province is located in the lower reaches of the Yangtze River along the East Coast of P.R. China (Fig. 1). It plays an important role in the Chinese growth of business and the socioeconomic changes and environmental upheavals (landslides, flooding) during the last few decades first resulted in an increase in the distribution of schistosomiasis here. The increased extent of snail habitats and intensity of transmission produced a highly endemic situation with higher numbers of acute 
cases then before (Huang and Manderson, 2005; Sun et al., 2008). As late as in 2004, 35 counties in Jiangsu province were endemic with 39 acute cases reported (Huang et al., 2004; Yang et al., 2005). Responding to this, the provincial government revised control strategies in 2005, strengthening integrated measures such as applying expanded chemotherapy for humans and bovines together with snail elimination, improved water supply, sanitation, personal protection and health education (Sun et al., 2011). These extensive, integrated control activities were successful and all endemic counties in Jiangsu province had reached the criterion of transmission control by 2010 (i.e. infection levels below $1 \%$ both in humans and livestock and no infected snails found during routine surveys) transforming the province into a low-endemic area (Hong et al., 2011; Sun et al., 2011, 2012). However, low levels of infection persist, and this together with the relative insensitivity of the Kato-Katz stool examination technique makes it difficult to identify the extent of risk (Lin et al., 2008). Since a technique capable of reliably detecting low levels of transmission is critical for schistosomiasis control, we developed an integrated approach consisting of water contact studies based on sentinel mice and spatio-temporal analysis to assess the infection risk and explore the potential for moving towards complete elimination of schistosomiasis transmission (Collins et al., 2012). The presentation is the summary of a number of transmission projects carried out in various areas along the Yangtze River during 3 years.

\section{Materials and methods}

\section{Study area and time periods}

Studies took place from 2009 to 2011 between May and September of each year in the marshlands along the Yangtze River within Jiangsu province. The investigations covered 19 counties and the total length of river bed investigated was about $180 \mathrm{~km}$. The sites chosen for monitoring (Fig. 1) were selected based on the following factors:

(i) assembly centres of mobile boatmen and fishermen in snail-containing environments;

(ii) assembly centres of large enterprises, construction projects and docks along the Yangtze River;

(iii) administrative boundaries of villages;

(iv) sites where infected snails have been found in the past 3 years; and

(v) livestock grazing areas and waterways in direct connection with the Yangtze River.

\section{Sentinel mice}

A mouse bioassay was developed to standardise and improve the sensitivity of water contact studies for schistosomiasis risk. It consisted of wire cages, each with 20 mice weighing $20 \mathrm{~g}$ or more, that could be suspended at the water surface to ensure that tails, paws and portions of the lower abdomen touched the water. The cages were deployed at various sites along the river on a monthly basis exposing the mice to surface water for

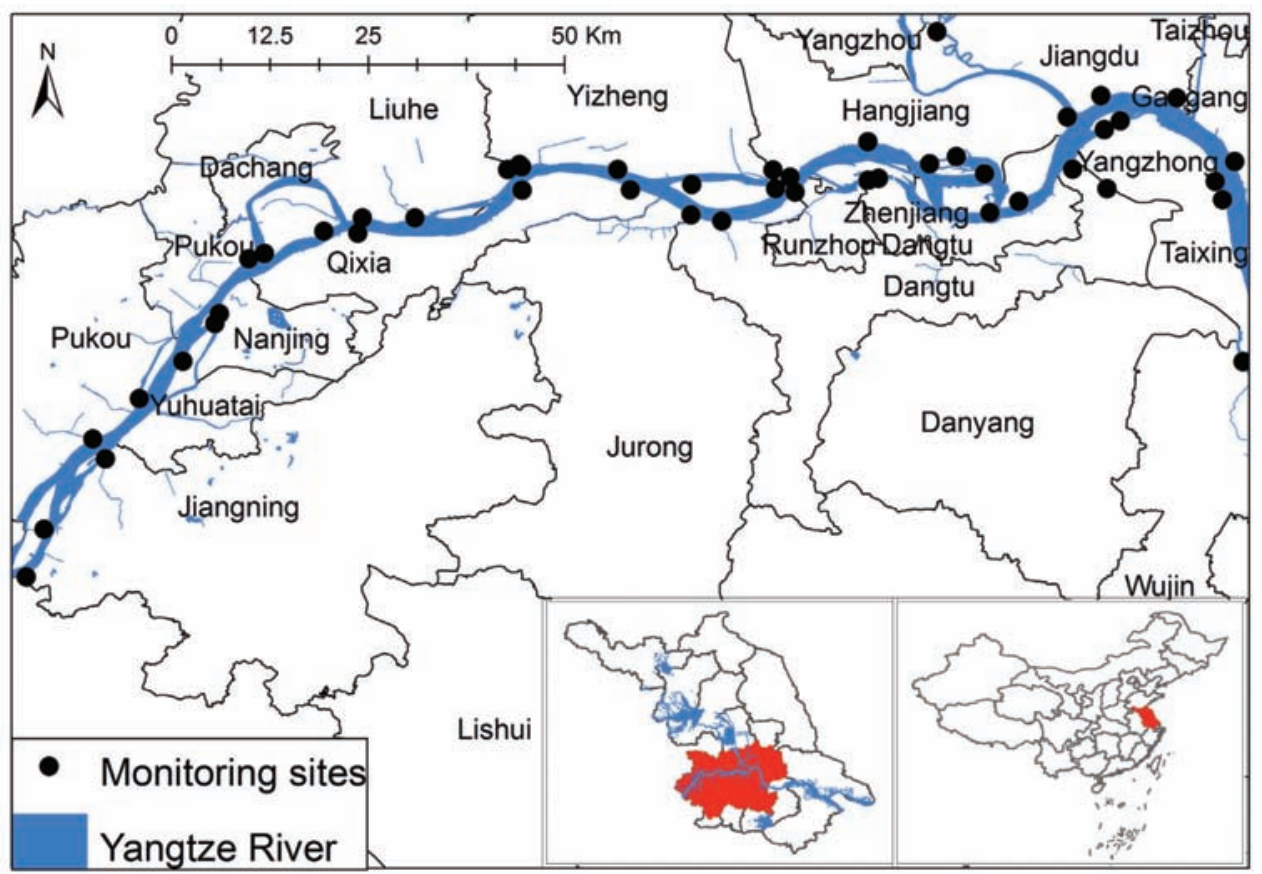

Fig. 1. The study region with the location of the surveillance sites in Jiangsu province, P.R. China. 
two consecutive days between 10:00 and 14:00 hours, after which the mice were brought to the laboratory and raised for 5 weeks to allow the development and maturation of any parasite resulting from an infection in the water. The mice were subsequently sacrificed, perfused and their livers sectioned and subjected to microscopy. Mice with adult schistosome worms in their veins or with eggs in their livers were recorded as infected.

One project in 2009 was based on 45 sites along the river, whilst others in 2010 and 2011, respectively, utilised 50 sites. Geographical coordinates (latitude/longitude) at each site were recorded by a hand-hold geographical positioning service (GPS) device (Garmin Map76 (Garmin Corp; Taiwan)). The GPS data and the laboratory results emanating from the sentinel mice were integrated into a geographical information system (GIS) database to assess the infection risk. The following three indexes were used:

(i) the proportion of sites with infected mice, i.e. the number of surveillance sites with positive mice compared to the total number of surveillance sites;

(ii) the proportion of infected sentinel mice, i.e. the number of positive sentinel mice out of the effective number of sentinel mice, i.e. the total number of mice minus those that succumbed and died for various reason during the field work; and

(iii) the average worm burden, i.e. the total number of worms recovered in relation to the total number of positive sentinel mice.

\section{Ethical approval}

All mice studies described here were approved by the Ethics Review Committee of Jiangsu Institute of Parasitic Diseases, P.R. China (permission no. JIPDERC2007008).

\section{Statistical analysis}

\section{Primary descriptive analysis}

The changes over time at the positive sites, rates and worm burdens were first explored through visual inspection including calculation of the mean values and dispersions, then compared using a $\chi^{2}$ test. The analyses were performed using SPSS (version 11, SPSS Inc. Chicago, USA).

\section{Spatio-temporal analysis}

All spatially explicit analyses were carried out using the spatial analyst module of ArcGIS 10.0 (ESRI;
Redlands, USA), which has been widely applied in many fields of research (Oyana et al., 2006; Lai et al., 2009; Svensson et al., 2009; Naparus and Kuntner, 2012). The standard deviational ellipse (SDE) measures the spatial distribution of geographical features and provides information about dispersion in terms of orientation and deviation. The "directional distribution application" was used to measure whether the distribution at the positive sites, the positive rates and worm burdens exhibited an annual, directional trend and to provide information about dispersion in terms of compactness and orientation. Distributional trend analysis was used to create a feature class containing an elliptical polygon centred on the mean centre for all features under investigation. The attribute values for these output ellipse polygons were three-fold, i.e. the two standard distances (the long and the short axis) plus the orientation of the ellipse. One standard deviation (SDE1) was used to represent the ellipse polygon covering approximately $68 \%$ of all input feature centroids (Svensson et al., 2009; Naparus and Kuntner, 2012). A series of measurements and data including axial ratios, length of the long axis, length of the short axis and the feature coordinates for each ellipse were collected to compare the spatial risk patterns.

The SaTScan ${ }^{\mathrm{TM}}$ method has become an increasingly popular adjunct for exploring the spatio-temporal distribution of infectious diseases (Kulldorff, 2001; Kulldorff et al., 2005; Higgs et al., 2007), and more and more studies in P.R. China use it to confirm cluster results and to explore disease patterns (Zhang et al., 2008; Li et al., 2009; Zhao et al., 2010). Clusters of the positive rates of sentinel mice were identified by this methodology. SaTScan ${ }^{\mathrm{TM}}$ (version 9.1) was used to identify clusters of high and low risk by the space-time permutation model, defined by a cylindrical window constrained to clusters with both the proportion of the population at risk and study periods less than 50\% (Coleman et al., 2009; Le et al., 2012). Relative risk (RR) for each cluster was alao caculated. RR is the estimated risk within the cluster divided by the estimated risk outside the cluster. It is calculated as the observed divided by the expected within the cluster divided by the observed divided by the expected outside the cluster. The mathematical notation is:

$$
R R=\frac{c / E[c]}{(C-c) /(C-E[c])}
$$

where the number of $c$ is observed cases within the cluster, $C$ is the total number of cases in the data set and $E[c]$ is the expected number of cases within the cluster (Mainassara et al., 2010). Monte Carlo simulations (999 times) were used for significance testing at the 0.05 level. 


\section{Results}

Tables 1 and 2 summarise the results of the bioassay by month and year. Altogether, 18 positive sites were recorded out of the total of 725 corresponding to a positive rate of $2.5 \%$, while the number of infected mice discovered was only 53 out of all the mice deployed over the 3 -year period $(13,100)$ corresponding to a positive rate of $0.40 \%$. A total of 167 adult schistosome worms were collected from these 53 positive mice giving an average worm burden of just above 3 worms per mouse (3.15). The monthly and yearly ranges over the 3 years were 2.00-5.70 and 2.30-4.00, respectively.

Figs. 2 and 3 show the developments over time for the study sites sentinel mice by month and year. The variances were significant $(P<0.01)$. Fig. 2 shows a minimum around July and indicates increased risk in the beginning and end of the season with two peaks of infection: one in June and one in September. The graph in Fig. 3 shows clearly the declining rates. Interestingly, however, even if the number of infectious sites declined strongly from 2009 to 2011, the risk at each infectious site actually climbed slightly in 2011.

Fig. 4 shows the series of directional distributions of the positive rates of sentinel sites, mice and worm burdens. The purple, green and red ellipses represent the directional distributions for 2009, 2010 and 2011, respectively. These directional distributions were simi- lar and the ellipse orientations were always oriented along the Yangtze River. From 2009 to 2010, the lengths of both axes became increasingly reduced, indicating that the standard deviations of the ellipses were decreasing. Fig. 5 shows the overall, directional distribution of the positive rates of sentinel sites, mice and worm burdens. The orientation of the ellipses was similar, but both worm burden axes were shorter than those of the other two, indicating that the standard deviation of the worm burdens was lower.

Table 3 and Fig. 6 present the results of the scan statistics for the positive sentinel mice and the distribution of the cluster circles. Four statistically significant clusters wer discovered in 2009 but in 2010 and 2011, there was only one each year. Dantu was the only county that presented a cluster for every year investigated. The clustering occurred in June and September with the relative risk being the highest in June.

\section{Discussion}

Spatio-temporal identification of regions at risk for schistosomiasis infection is the first step when replacing general control activities by a move towards elimination. In line with the remarkable progress in schistosomiasis control made in P.R. China over the last 60 years, Jiangsu province has become a low-endemic area. However, the extent of infection risk is assessed on conventional surveillance systems, focused on

Table 1. Summary of monthly findings from 2009 to 2011.

\begin{tabular}{lcccccccc}
\hline Month & $\begin{array}{c}\text { No. of sites } \\
\text { investigated }\end{array}$ & $\begin{array}{c}\text { Positive } \\
\text { sites }\end{array}$ & $\begin{array}{c}\text { Positive rate } \\
\text { at the site* }\end{array}$ & $\begin{array}{c}\text { Total number } \\
\text { of mice }\end{array}$ & $\begin{array}{c}\text { Mice found } \\
\text { positive }\end{array}$ & $\begin{array}{c}\text { Positive rate } \\
\text { in mice** }\end{array}$ & $\begin{array}{c}\text { Worms per } \\
\text { mouse }\end{array}$ & $\begin{array}{c}\text { Average worm } \\
\text { burden }\end{array}$ \\
\hline May & 145 & 2 & $1.4 \%$ & 2,749 & 8 & $0.29 \%$ & 28 & 3.50 \\
June & 145 & 4 & $2.8 \%$ & 2,633 & 8 & $0.30 \%$ & 16 & 2.00 \\
July & 145 & 2 & $1.4 \%$ & 2,660 & 3 & $0.11 \%$ & 17 & 5.67 \\
August & 145 & 2 & $1.4 \%$ & 2,475 & 19 & $0.77 \%$ & 61 & 3.21 \\
September & 145 & 8 & $5.5 \%$ & 2,593 & 15 & $0.58 \%$ & 45 & 3.00 \\
Total & 725 & 18 & $2.5 \%$ & 13,110 & 53 & $0.40 \%$ & 167 & 3.15 \\
\hline
\end{tabular}

$\chi^{2}=7.75, \mathrm{P}=0.101 ; * \chi^{2}=17.22, \mathrm{P}=0.002$.

Table 2. Summary of annual findings.

\begin{tabular}{lcccccccc}
\hline Year & $\begin{array}{c}\text { No. of sites } \\
\text { investigated }\end{array}$ & $\begin{array}{c}\text { Positive } \\
\text { sites }\end{array}$ & $\begin{array}{c}\text { Positive rate } \\
\text { at the site* }\end{array}$ & $\begin{array}{c}\text { Total number } \\
\text { of mice }\end{array}$ & $\begin{array}{c}\text { Mice found } \\
\text { positive }\end{array}$ & $\begin{array}{c}\text { Positive rate } \\
\text { in mice** }\end{array}$ & $\begin{array}{c}\text { Worms per } \\
\text { mouse }\end{array}$ & $\begin{array}{c}\text { Average worm } \\
\text { burden }\end{array}$ \\
\hline 2009 & 225 & 13 & $5.8 \%$ & 4,355 & 23 & $0.53 \%$ & 53 & 2.30 \\
2010 & 250 & 3 & $1.2 \%$ & 4,252 & 12 & $0.28 \%$ & 42 & 3.50 \\
2011 & 250 & 2 & $0.8 \%$ & 4,503 & 18 & $0.40 \%$ & 72 & 4.00 \\
Total & 725 & 18 & $2.5 \%$ & 13,110 & 53 & $0.40 \%$ & 167 & 3.15 \\
\hline
\end{tabular}

$* \chi^{2}=14.71, \mathrm{P}=0.001 ; * \chi^{2}=3.24, \mathrm{P}=0.198$. 


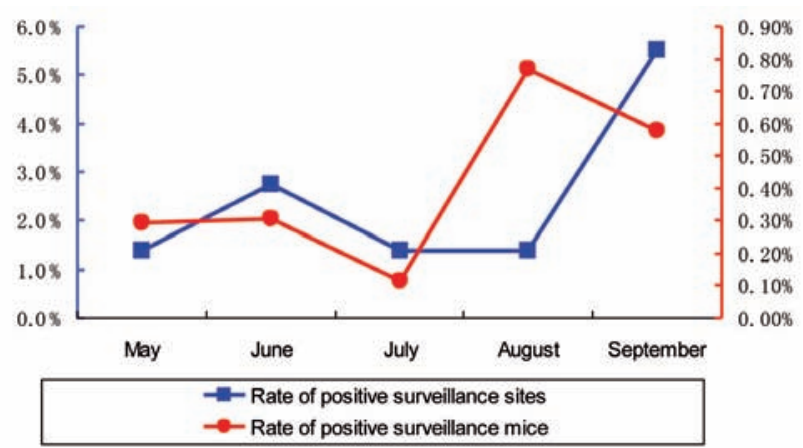

Fig. 2. The monthly positive rates.

humans and the intermediate host, which are not sufficiently sensitive. The mouse bioassay for risk detection, expressed by the presence of cercariae in the water, has become increasingly used as an early warning system (EWS) for schistosomiasis (Spear et al., 2004; Worrell et al., 2011). We preferred this approach as it is a considerably more sensitive than conventional stool examination and lends itself to standardisation.

The impact of ecological factors on the transmission
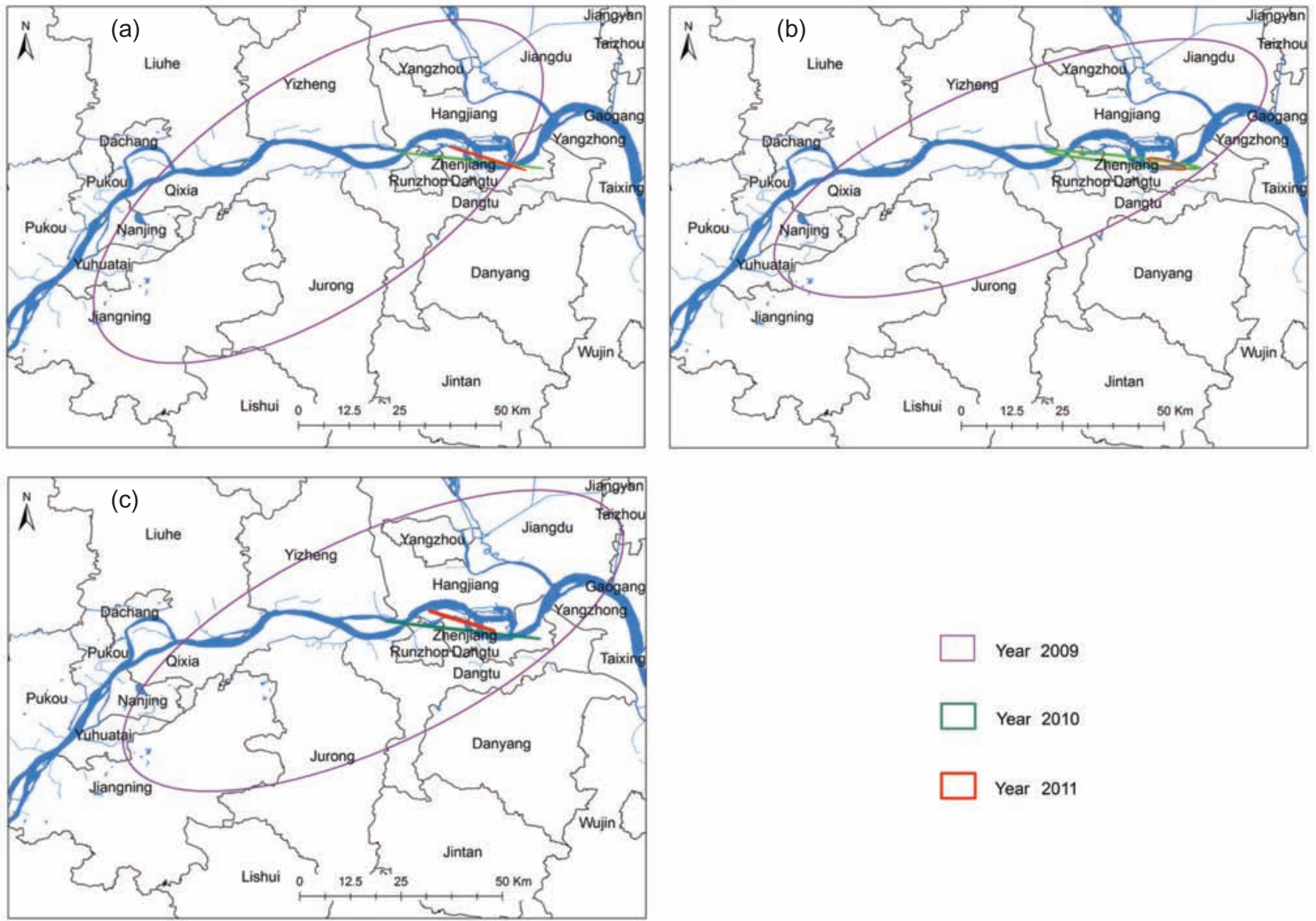

Year 2009

Year 2010

Year 2011

Fig. 4. The directional distribution of the positive rates of surveilance sites (A), sentinel mice (B) and their average worm burden (C). 


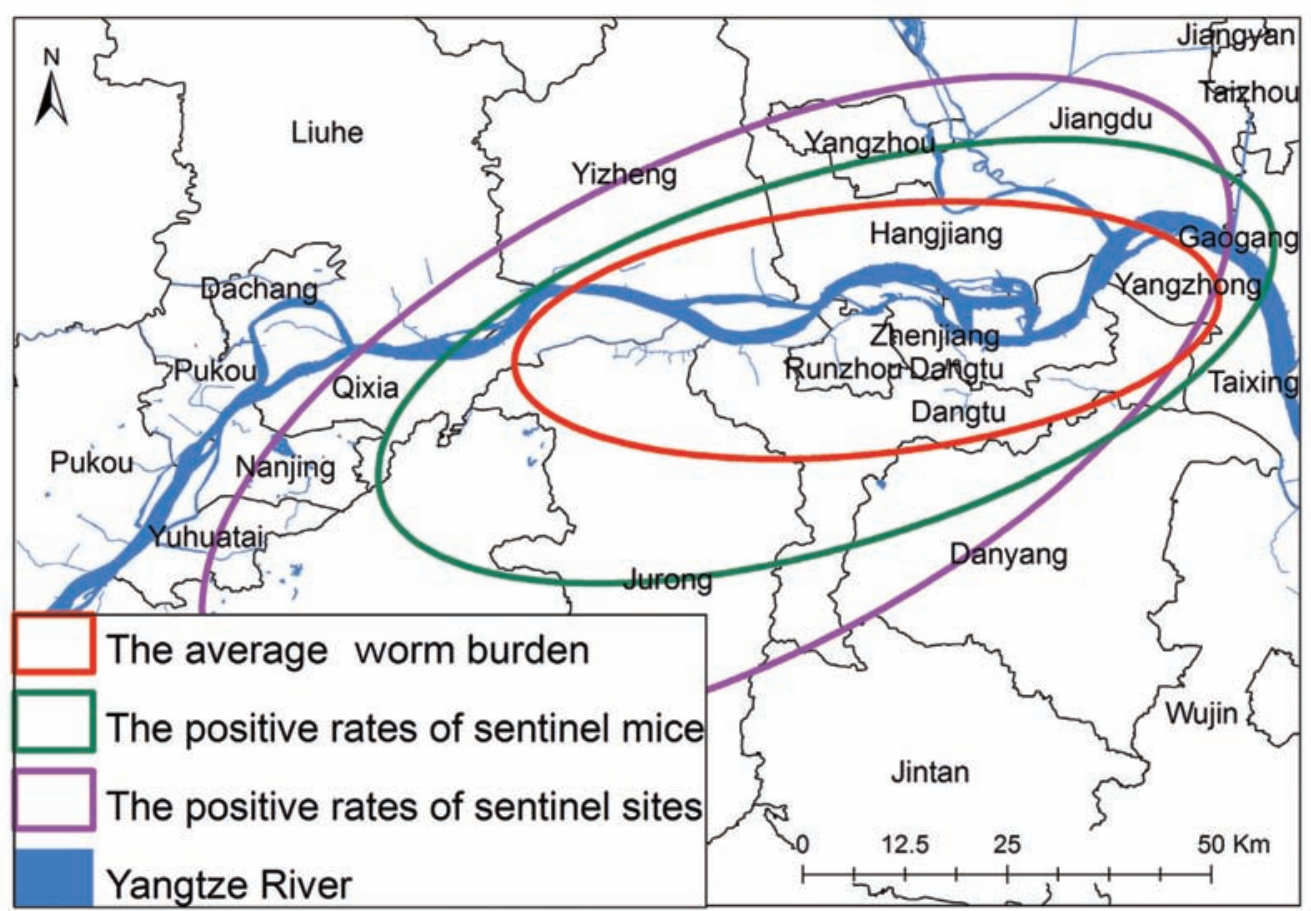

Fig. 5. The overall directional distribution of the positive rates of mice in sentinel sites and the average worm burden.

identify potential populations and factors of interest for further investigation (Wu et al., 2007; Yang et al., 2008; Malone et al., 2010). The studies referred to above were carried out in areas at medium to high levels of endemicity, while we were primarily interested in particularly low levels of endemicity. Indeed, the spatio-temporal analysis of the mouse bioassay data made it possible to identify the level of risk not only with regard to time and location but, importantly, also to do so in situations characterised by an extremely lowlevel of endemicity.

The comparatively high numbers of mice used in the different years were needed because of the very long stretch of the Yangtze River and to the high number of people living along its edges. This need was further strengthened due to the fact that the success of the control programme had already suppressed the infection levels both in humans and livestock below $1 \%$ in Jiangsu province making infections difficult to find (Hong et al., 2011; Sun et al., 2011, 2012).

Taken together, the investigations described here showed significant differences between the positive rates of surveillance sites and sentinel mice in different months and years already at the descriptive level of analysis. The positive rates were the highest in the project carried out in 2009 and decreasing gradually over the 3 years covered to reach the lowest levels in 2011. This development can be explained by the strengthening of snail control with niclosamide that took place in the high-risk regions (Wang et al., 2009; Yang et al., 2010). In contrast, however, the average worm burden increased from 2.3 to 4.0 during the whole 3-year period indicating that infection transmission intensity remained serious in some areas.

The SDE approach has many applications. For example, mapping the distributional trend for a certain type of crime might identify a relationship with particular features, e.g. a string of bars or restaurants (Scott and Janikas, 2010). It can also visualise the degree of various distribution dispersions (Yuill, 1971; Khan, 1986; Gong, 2002; Tenzin et al., 2010) and provide applications for how disease outbreaks spread (Mitchell, 2005). In our studies, three parameters were used to describe and define the standard deviational ellipse, namely the angle of rotation for the distribution direction and the deviations along the long and the short axis for the degree of dispersion. As Fig. 4 shows, the spatial distribution patterns of the positive rates at the sentinel sites, the mice and the worm burdens were similar. In addition, the orientation of the ellipses along the Yangtze River indicated very clearly that the river was the focus of risk. Both the long and the short axis decreased significantly between 2009 and 2011, presenting increasingly compact ellipses over time with the main risk concentrated in Dantu county. The results confirm that schistosomiasis transmission has been significantly reduced in Jiangsu province since the implementation of the long-term control plan by the provin- 
Table 3. Significant clusters found by the SaTScan for the positive sentinel mice in the study area.

\begin{tabular}{llllccc}
\hline Year & Month & County & Cluster location & Cluster radius $(\mathrm{km})$ & Relative risk (RR) & P-value \\
\hline \multirow{2}{*}{2009} & May & Dantu & $32.236 \mathrm{~N}$ and $119.379 \mathrm{E}$ & 0 & 3.13 & 0.050 \\
& June & Liuhe & $32.190 \mathrm{~N}$ and $118.950 \mathrm{E}$ & 11.73 & 11.50 & 0.050 \\
& August & Hangjiang & $32.245 \mathrm{~N}$ and $119.360 \mathrm{E}$ & 0 & 4.60 & 0.022 \\
2010 & September & Yangzhong & $32.290 \mathrm{~N}$ and $119.730 \mathrm{E}$ & 4.29 & 1.53 & 0.050 \\
2011 & June & Dantu & $32.224 \mathrm{~N}$ and $119.363 \mathrm{E}$ & 0 & 2.00 & 0.011 \\
& August & Dantu & $32.235 \mathrm{~N}$ and $119.481 \mathrm{E}$ & 0 & 2.00 & 0.011 \\
\hline
\end{tabular}

cial government, especially after 2009. Fig. 5 shows that both the worm burden axes were shorter than the positive rates of sentinel mice and sites, which indicates the deviation of transmission intensity was lower. It also tells us that the transmission intensity, although previously very high, decreased over the 3 years. The possibility that transmission was tempered not long ago and could have left occasional definite hosts (livestock or humans) with a high worm burden is the most probable explanation for the unexpected increase of the average worm burden detected in the infected mice in 2011.

The SaTScan ${ }^{\mathrm{TM}}$ method has become an increasingly popular adjunct for exploring the spatio-temporal distribution of infectious diseases (Kulldorff, 2001; Kulldorff et al., 2005; Higgs et al., 2007), and more and more studies in P.R. China use it to confirm clus- ter results with respect to schistosomiasis and to further explore disease patterns (Zhang et al., 2008; Li et al., 2009). We used scan statistics to identify the spatio-temporal clusters finding four significant such clusters in 2009 with high numbers of positive sentinel mice, but only one in 2011 (located in Dantu county). This particular high risk is best explained by the environmental setting. First, the geographical location of the cluster was on an island in the Yangtze River with a high density of snails and a large area of snail habitats (Zhou et al., 2001; Dai et al., 2011). Second, a small ferry connects the island with the mainland, contributing to a stronger activity of mobile people resulting in more people at risk (Wu et al., 1993; Steinmann et al., 2006). Third, available local, control resources were insufficient (Utzinger et al., 2005; Zhou et al., 2005). After the revelation of this remaining cluster in

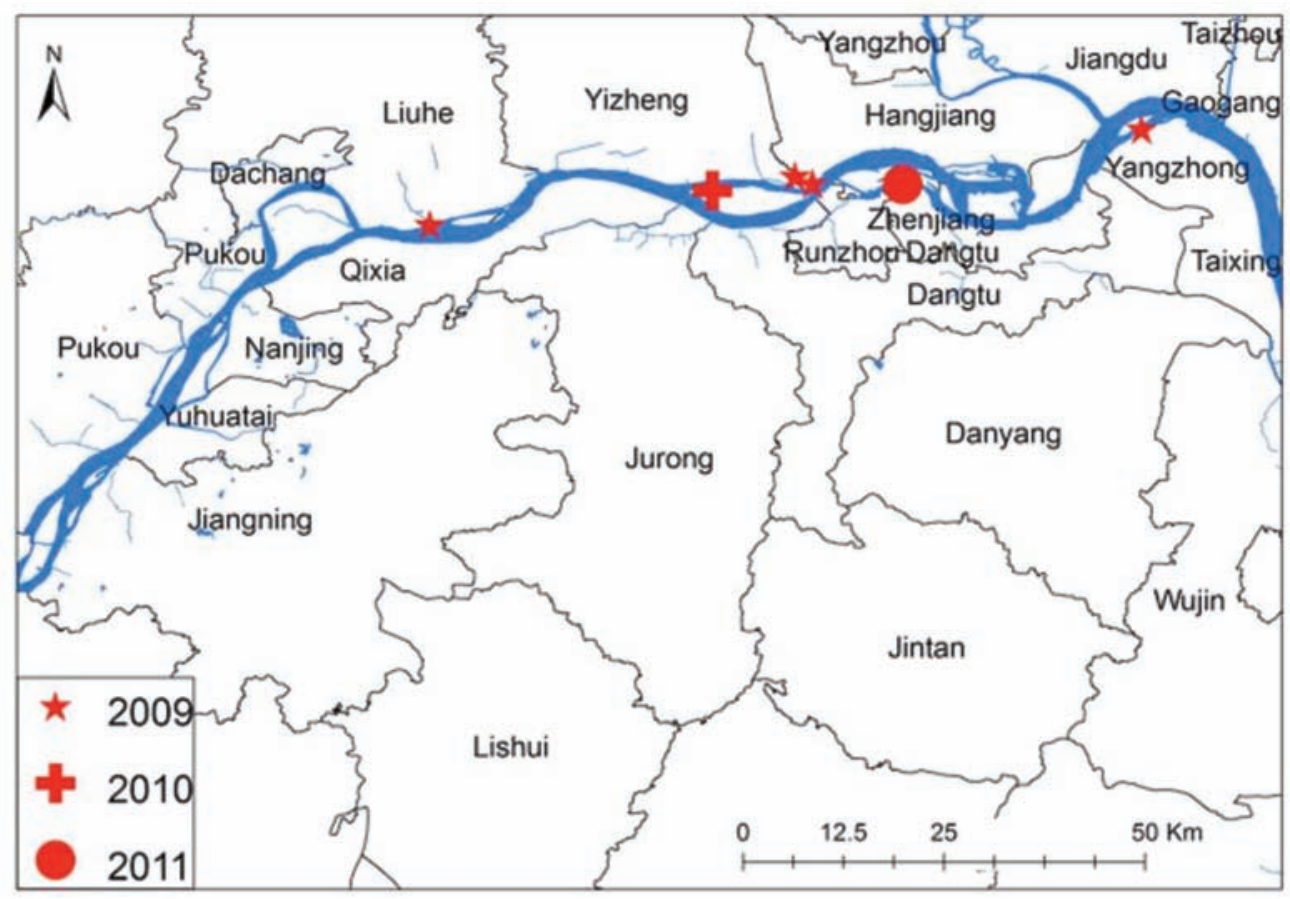

Fig. 6. Significant clusters of positive sentinel mice. 
Dantu, more health resources assigned to this area resulting in the interruption of schistosomiasis transmission also in this area. However, although the approach described here was successful, the spatial distribution of schistosomiasis may be multifactorial and accuracy of the model might need to be further improved.

The discovery of two infection peaks in the study region, already apparent in the descriptive analysis, was confirmed by Scan statistics that showed that there were temporal clusters both in June and September. This two-peak transmission pattern is consistent with previous reports and can be explained by the evolvement of the snail populations and the length of the schistosome life cycle in P.R. China (Zhang et al., 1990; Wilke et al., 2000; Zhou et al., 2011). It means that cercariae were first shed from infected snails around June and infecting their definitive hosts around this time, providing the time needed to mature into worms and complete their life cycle resulting in a new generation of infected snails beginning the shedding cycle in September.

\section{Conclusions}

The development of better assessment for infection risk has become critical with improved control efforts continuously decreasing schistosomiasis transmission levels. The projection of surveillance replacing active control requires that an optimal approach, an EWS as it were, is in place. The creation of an investigative framework, capable of identifying risk through an integrated approach, should assist in designing evidence-based control strategies to be applied in the process of schistosomiasis elimination in P.R. China (Zhou et al. 2013).

\section{Acknowledgements}

The authors would like to acknowledge the staff at local Center for Disease Control and Prevention for their kind collaboration and making the field data available. This work received financial support from the National Natural Science Foundation of China (nos. 81101275 and 81101280), Natural Science Foundation of Jiangsu province (BS2010153), Project of Public Health Department of Jiangsu province (no. RC2011094), the Chinese Important Scientific Research Project on Infectious Diseases (no. 2012ZX10004-220), and partial funding from through a capacity building initiative for EcoHealth Research on Emerging Infectious Disease in Southeast Asia, supported by the International Development Research Centre (IDRC).

\section{References}

Bergquist R, Rinaldi L, 2010. Health research based on geospatial tools: a timely approach in a changing environment. J Helminthol 84, 1-11.

Coleman M, Mabuza AM, Kok G, Coetzee M, Durrheim DN, 2009. Using the SaTScan method to detect local malaria clusters for guiding malaria control programmes. Malar J 8, 68 .

Collins C, Xu J, Tang S, 2012. Schistosomiasis control and the health system in P.R. China. Infect Dis Poverty 1, 8.

Dai M, Shen XH, Li YF, Chen XP, Zhang LH, Wang L, Hong QB, Yang GJ, 2011. Surveillance of schistosomiasis in a national, surveillance site of Dantu district, Zhenjiang city, 2005-2009. Chin J Schisto Control 23, 619-641.

Gong J, 2002. Clarifying the standard deviational ellipse. Geogr Anal 34, 155-167.

Hao Y, Wu XH, Xia G, Zheng H, Guo JG, Wang LY, Zhou XN, 2006. Schistosomiasis situation in People's Republic of China in 2005. Chin J Schisto Control 18, 321-324.

Higgs BW, Mohtashemi M, Grinsdale J, Kawamura LM, 2007. Early detection of tuberculosis outbreaks among the San Francisco homeless: trade-offs between spatial resolution and temporal scale. PLoS One 2, e1284.

Hong QB, Yang K, Huang YX, Sun LP, Yang GJ, Gao Y, Zhang LH, Zhou M, Steinmann P, Liang YS, 2011. Effectiveness of a comprehensive schistosomiasis japonica control program in Jiangsu province, China, from 2005 to 2008. Acta Trop 120, S151-S157.

Huang YX, Manderson L, 2005. The social and economic context and determinants of schistosomiasis japonica. Acta Trop 96, 223-231.

Huang YX, Sun LP, Hong QB, Gao Y, Zhang LH, Gao Y, Chen H, Guo JH, Liang YS, Zhu YC, 2004. Longitudinal observation on fluctuation trend of distribution and spread of Oncomelania snails after floodwater in marshland of lower beaches of Yangtze River. Chin J Schisto Control 16, 253-256. Khan AA, 1986. Two simple methods of spatial analysis and their applications in location-oriented health services research. Am J Public Health 76, 1207-1209.

Kulldorff M, 2001. Prospective time periodic geographical disease surveillance using a scan statistic. J R Stat Soc Ser A Stat Soc 164, 61-72.

Kulldorff M, Heffernan R, Hartman J, Assuncao R, Mostashari F, 2005. A space-time permutation scan statistic for disease outbreak detection. PLoS Med 2, e59.

Lai PC, Low CT, Wong M, Wong WC, Chan MH, 2009. Spatial analysis of falls in an urban community of Hong Kong. Int J Health Geogr 8, 14.

Le H, Poljak Z, Deardon R, Dewey CE, 2012. Clustering of and risk factors for the porcine high fever disease in a region of Vietnam. Transbound Emerg Dis 59, 49-61.

Li SZ, Luz A, Wang XH, Xu LL, Wang Q, Qian YJ, Wu XH, 
Guo JG, Xia G, Wang LY, Zhou XN, 2009. Schistosomiasis in China: acute infections during 2005-2008. Chin Med J 122, 1009-1014.

Lin DD, Liu JX, Liu YM, Hu F, Zhang YY, Xu JM, Li JY, Ji MJ, Bergquist R, Wu GL, Wu HW, 2008. Routine Kato-Katz technique underestimates the prevalence of Schistosoma japonicum: a case study in an endemic area of the People's Republic of China. Parasitol Int 57, 281-286.

Mainassara HB, Molinari N, Demattei C, Fabbro-Peray P, 2010. The relative risk of spatial cluster occurrence and spatiotemporal evolution of meningococcal disease in Niger, 2002-2008. Geospat Health 5, 93-101.

Malone JB, Yang GJ, Leonardo L, Zhou XN, 2010. Implementing a geospatial health data infrastructure for control of Asian schistosomiasis in the People's Republic of China and the Philippines. Adv Parasitol 73, 71-100.

Mitchell A, 2005. The ESRI Guide to GIS Analysis, Volume 2. ESRI Press.

Naparus M, Kuntner M, 2012. A GIS model predicting potential distributions of a lineage: a test case on hermit spiders (Nephilidae: Nephilengys). PLoS One 7, e30047.

Oyana TJ, Dai D, Scott KE, 2006. Spatiotemporal distributions of reported cases of the avian influenza H5N1 (bird flu) in Southern China in early 2004. Avian Diseases 50, 508-515.

Scott LM, Janikas MV, 2010. Spatial statistics in ArcGIS. Handbook of Applied Spatial Analysis, 27-41.

Simoonga C, Kazembe LN, Kristensen TK, Olsen A, Appleton CC, Mubita P, Mubila L, 2008. The epidemiology and smallscale spatial heterogeneity of urinary schistosomiasis in Lusaka province, Zambia. Geospat Health 3, 57-67.

Spear RC, Zhong B, Mao Y, Hubbard A, Birkner M, Remais J, Qiu D, 2004. Spatial and temporal variability in schistosome cercarial density detected by mouse bioassays in village irrigation ditches in Sichuan, China. Am J Trop Med Hyg 71, 554-557.

Steinmann P, Keiser J, Bos R, Tanner M, Utzinger J, 2006. Schistosomiasis and water resources development: systematic review, meta-analysis, and estimates of people at risk. Lancet Infect Dis 6, 411-425.

Sun LP, Liang YS, Huang YX, Hong QB, Yang G, Zhang LH, Gao Y, Xie CY, 2008. Evaluation on effect of infection control of schistosomiasis in Jiangsu province. Chin J Schisto Control 20, 13-17.

Sun LP, Tian ZX, Yang K, Huang YX, Gao Y, Wu WQ, Qiu ZJ, Yang GJ, Min J, Ge J, Liang YS, Gao Q, Wu HH, 2012. Effect evaluation of transmission control of schistosomiasis in 14 counties (cities, districts) of Jiangsu province. Chin J Schisto Control, 32-37.

Sun LP, Wang W, Liang YS, Tian ZX, Hong QB, Yang K, Yang GJ, Dai JR, Gao Y, 2011. Effect of an integrated control strategy for schistosomiasis japonica in the lower reaches of the Yangtze River, China: an evaluation from 2005 to 2008. Parasit Vectors 4, 243.
Svensson K, Back E, Eliasson H, Berglund L, Granberg M, Karlsson L, Larsson P, Forsman M, Johansson A, 2009. Landscape epidemiology of tularemia outbreaks in Sweden. Emerg Infect Dis 15, 1937-1947.

Tenzin T, Sharma B, Dhand NK, Timsina N, Ward MP, 2010. Reemergence of rabies in Chhukha district, Bhutan, 2008. Emerg Infect Dis 16, 1925-1930.

Utzinger J, Zhou XN, Chen MG, Bergquist R, 2005. Conquering schistosomiasis in China: the long march. Acta Trop 96, 69-96.

Wang LD, Chen HG, Guo JG, Zeng XJ, Hong XL, Xiong JJ, Wu XH, Wang XH, Wang LY, Xia G, Hao Y, Chin DP, Zhou XN, 2009. A strategy to control transmission of Schistosoma japonicum in China. N Engl J Med 360, 121-128.

Wilke T, Davis GM, Cui EC, Zhou XN, Xiao Peng Z, Yi Z, Spolsky CM, 2000. Oncomelania hupensis (Gastropoda: Rissooidea) in eastern China: molecular phylogeny, population structure, and ecology. Acta Trop 77, 215-227.

Worrell C, Xiao N, Vidal JE, Chen L, Zhong B, Remais J, 2011. Field detection of Schistosoma japonicum cercariae in environmental water samples by quantitative PCR. Appl Environ Microb 77, 2192-2195.

Wu XH, Wang XH, Utzinger J, Yang K, Kristensen TK, Bergquist R, Zhao GH, Dang H, Zhou XN, 2007. Spatio-temporal correlation between human and bovine schistosomiasis in China: insight from three national sampling surveys. Geospat Health 2, 75-84.

Wu Z, Bu K, Yuan L, Yang G, Zhu J, Liu Q, 1993. Factors contributing to reinfection with schistosomiasis japonica after treatment in the lake region of China. Acta Trop 54, 83-88.

Yang GJ, Vounatsou P, Zhou XN, Tanner M, Utzinger J, 2005. A Bayesian-based approach for spatio-temporal modeling of county level prevalence of Schistosoma japonicum infection in Jiangsu province, China. Int J Parasitol 35, 155-162.

Yang GJ, Li W, Sun LP, Wu F, Yang K, Huang YX, Zhou XN, 2010. Molluscicidal efficacies of different formulations of niclosamide: result of meta-analysis of Chinese literature. Parasit Vectors 3, 84.

Yang K, Wang XH, Yang GJ, Wu XH, Qi YL, Li HJ, Zhou XN, 2008. An integrated approach to identify distribution of Oncomelania bupensis, the intermediate host of Schistosoma japonicum, in a mountainous region in China. Int J Parasitol 38, 1007-1016.

Yang K, Zhou XN, Wu XH, Steinmann P, Wang XH, Yang GJ, Utzinger J, Li HJ, 2009. Landscape pattern analysis and Bayesian modeling for predicting Oncomelania hupensis distribution in Eryuan county, People's Republic of China. Am J Trop Med Hyg 81, 416-423.

Yuill RS, 1971. The standard deviational ellipse; an updated tool for spatial description. Geogr Ann B 53, 28-39.

Zhang S, Liu Z, Hu L, Xie Z, Yuan S, Yan J, Zhong J, Hu G, Zhou S, Sun Y, 1990. Studies on epidemiological factors and 
regular partterns of schistosomiasis in Boyang Lake region. Chin J Schisto Control 2, 17-23.

Zhang Z, Carpenter TE, Chen Y, Clark AB, Lynn HS, Peng W, Zhou Y, Zhao G, Jiang Q, 2008. Identifying high-risk regions for schistosomiasis in Guichi, China: a spatial analysis. Acta Trop 107, 217-223.

Zhao F, Zhu R, Zhang LJ, Zhang ZJ, Li YP, He MZ, Zhou YB, Guo JG, Zhao GM, Jiang QW, 2010. Integrated detection and analysis on the clusters of schistosomiasis based on geographic information system. Chin J Epidemiol 31, 1272-1275.

Zhou XN, Bergquist R, Tanner M, 2013. Elimination of tropical disease through surveillance and response. Infect Dis Poverty 2, 1.

Zhou XN, Malone JB, Kristensen TK, Bergquist NR, 2001. Application of geographic information systems and remote sensing to schistosomiasis control in China. Acta Trop 79, 97-106.
Zhou XN, Guo JG, Wu XH, Jiang QW, Zheng J, Dang H, Wang XH, Xu J, Zhu HQ, Wu GL, 2007. Epidemiology of schistosomiasis in the People's Republic of China, 2004. Emerg Infect Dis 10, 1470-1477.

Zhou XN, Lv S, Yang GJ, Kristensen TK, Bergquist NR, Utzinger J, Malone JB, 2009. Spatial epidemiology in zoonotic parasitic diseases: insights gained at the 1 st International Symposium on Geospatial Health in Lijiang, China, 2007. Parasit Vectors 2, 10.

Zhou XN, Wang LY, Chen MG, Wu XH, Jiang QW, Chen XY, Zheng J, Utzinger J, 2005. The public health significance and control of schistosomiasis in China-then and now. Acta Trop 96, 97-105.

Zhou YB, Yang MX, Yihuo WL, Liu GM, Wang HY, Wei JG, Jiang QW, 2011. Effect of habitat fragmentation on the schistosome-transmitting snail Oncomelania hupensis in a mountainous area of China. Trans R Soc Trop Med Hyg 105, 189-196. 